\title{
El Know-How en radiología
}

\section{Know-How in radiology}

Heber T. Alonso-Que*

Servicio de Radiología e Imagen, Hospital Ángeles Clínica Londres, Ciudad de México, México

Nadie ha ascendido tan rápido al poder como Napoleón Bonaparte (1769-1821); para muchos era más que un general: era un genio. Pero no todos estaban impresionados, había generales prusianos que pensaban que era un afortunado; entre estos estaba Friedrich Ludwig, príncipe de Hohenlohe-Ingelfingen (17461818), dueño de un ilustre expediente militar, bajo las órdenes del propio Federico el Grande (1712-1786), el hombre que por sí solo había hecho de Prusia una gran potencia. Siempre había querido luchar contra Napoleón, y en agosto de 1806 el rey Federico Guillermo III de Prusia decidió declarar la guerra a Napoleón, por lo que Friedrich presentó un plan que asestaría un golpe devastador a los franceses. Sin embargo, el ejército de Napoleón marchaba con mochilas a la espalda, se movían con pasmosa celeridad y agilidad, mientras los prusianos usaban lentos carretones, perdiendo toda ventaja. El 14 de octubre, Napoleón alcanzó a Friedrich cerca de la ciudad de Jena; mientras este mantenía a su tropa en un estricto orden, los franceses eran verdaderos demonios por todos lados, y en cuestión de días no quedó prácticamente nada del antes poderoso ejercito prusiano.

Esto es un ejemplo histórico interesante de la realidad que enfrentaban los prusianos: se habían atrasado 50 años, y en lugar de responder a las circunstancias presentes repetían las fórmulas del pasado. Lo que alguna vez nos funcionó se vuelve doctrina, una barrera para protegernos de la realidad. Nos vence la costumbre, y la repetición reemplaza a la creatividad.

Hoy la radiología está en el camino de la toma de decisiones estratégicas basada en los desafíos científicos, tecnológicos y biotecnológicos más importantes de la historia, sumergida en la globalización, y ante una necesidad con carácter de aceptar nuevas posturas, nuevas ideas, incorporar la diversidad y la especificidad de otros, sin olvidar las características propias y 
limitantes de la especialidad. Debemos avanzar como Napoleón con Know-How (saber hacer o saber cómo), con una mente crítica, científica, analítica, ambiciosa, y con exactitud, flexibilidad, fuerza moral, empuje, tenacidad, seguridad, velocidad, simplicidad, carácter, con sed de aprendizaje, proactiva y propositiva, capaz de dar una opinión de alto impacto que desempeñe un papel de los más importantes en la toma de decisiones en la atención médica interdisciplinaria o multiprofesional.

La frase clásica del meme "correlacionar clínicamente» es una puerta fácil que no puede considerarse algo particular, ni siquiera peculiar de nuestra especialidad; es una costumbre. Actualmente es necesario hacer un análisis minucioso y una reflexión profunda intrínseca del papel que tenemos en la atención médica moderna del paciente. Hoy es menester evolucionar hacia una opinión o interconsulta de un especialista en radiología con criterios propios basados en la experiencia, la ciencia y el conocimiento, y no solo en el diagnóstico; ahora también nos incumben el pronóstico, lo terapéutico, la vigilancia y el seguimiento. Es la era del Know-How en radiología. 